\title{
On the Effect of SiC Content and Processing Temperature on Relative Density and Hardness of Hot Compacted Aluminum AA6061 Composite - Mathematical Empirical and Response Surface Approach
}

\author{
W. H. El-Garaihy ${ }^{1}$, S. E. Oraby ${ }^{2}$, El-Sayed M. A. Rassoul ${ }^{3} \&$ H. G. Salem ${ }^{4}$ \\ ${ }^{1}$ Mechanical Engineering Department, Faculty of Engineering, Suez Canal University, Egypt \\ ${ }^{2}$ Department of Manufacturing Engineering Technology, College of Technological Studies, PAAET, Kuwait \\ ${ }^{3}$ Production Engineering Department, Faculty of Engineering, Mansoura University, Egypt \\ ${ }^{4}$ Mechanical Engineering Department, Yousef Jamil Science and Technology Research Center (YJSTRC), \\ American University in Cairo, Egypt \\ Correspondence: W.H. El-Garaihy, Mechanical Engineering Department, Faculty of Engineering, Suez Canal \\ University, Ismailia, Egypt. Tel: 2-011-2957-0000. E-mail: wgaraihy@eng.suez.edu.eg.
}

Received: March 9, 2015 Accepted: April 3, 2015 Online Published: April 20, 2015

doi:10.5539/jmsr.v4n3p1 URL: http://dx.doi.org/10.5539/jmsr.v4n3p1

\begin{abstract}
The AA6061 is reinforced by adding $\mathrm{SiC}$ at various volume fractions and, the mixture is hot compacted at different processing temperatures. The influences of such parameters are investigated on the product relative density along with its relevant Vickers hardness using quantitative and qualitative formulation approach. Empirical relationships are established to relate each of the controlling (independent) parameters ( $\mathrm{SiC} \%$ and hot compaction (HC) temperature), to the composites relative density and the hardness, as dependent variables. The developed models are examined for its adequacy and significance using several statistical criteria. Response surface and contour graphs are established to reflect the relevant function interrelations and, to provide a data base source for the prior design stage.

Within the specified experimental domain, first order and nonlinear models are found independently adequate and significant to grasp the functional dependence between the relative density and both $\mathrm{SiC}$ and $\mathrm{HC}$ temperature. However, second order multiple model with quadratic components of $\mathrm{SiC}$ percent is found to best suit the hardness-SiC\%-temperature functional relationship.

Increasing $\mathrm{SiC}$ content is found to reduce the relative density of the composites regardless the hot compaction temperature while, up to about $18 \mathrm{vol} \% \mathrm{SiCp}$ relative ratio, it enormously and nonlinearly increases the composite hardness. Further increase in $\mathrm{SiC} \%$ addition seems not to affect the composite hardness. Relative density of the resulting composite is decreased by increasing $\mathrm{HC}$ temperature.
\end{abstract}

Keywords: AA6061, hot compact powder technology, relative density, vickers hardness, linear and nonlinear regression procedures, response surface methodology

\section{Introduction}

Aluminum alloys are notable by vast diversity in industrial application thanks to their many advantages regarding specific strength, corrosion resistance, thermal conductivity, low density, and good workability. On the other hand, their use is limited due to their relatively low yield strength and poor tribological characteristics (Min, 2009; O'Donnel et al., 2001). Therefore, applicability was affected negatively in many circumstances as a result of their reduced hardness and wear resistance (Huang et al., 2004). Recently, the interest to increase aluminum strength has risen and the study of metal matrix composites (MMCs) has been motivated in particular applications such as the aerospace and aeronautic industries. MMCs are considered as outstanding materials to obtain properties that are superior to those of the constituent phases and also to satisfy the above requirements. Aluminum is the most common metal used in MMCs; in particular, particles reinforced Aluminum-based MMCs are focal composites grasping an increasing attention recently thanks to their lightness, higher specific strength, and wear resistance (Senapati et al., 2014; Zakaria, 2014; Mohanakumara et al., 2014). 
Aluminium-Silicon alloys, as a matrix material, are frequently selected for their good wear resistance, strength-to-weight ratio, thermal conductivity, ease of fabrication at reasonable cost, high strength at elevated temperature, as well as excellent corrosion resistance. As a result of the previous mentioned properties, the suitability of these alloys for aerospace, automotive and military applications has been evident (Senapati et al., 2014; Rao \& Das, 2011). The strengthening of Aluminum and its alloys can be done by dispersing hard particles such as carbides, oxides, or nitrides into the aluminum matrix by using various techniques in the solid or liquid state (Pawar \& Utpat, 2014). $\mathrm{Al}_{2} \mathrm{O}_{3}$ and $\mathrm{SiC}$ reinforcements are two widely used types of reinforcing agents in aluminum metal matrix composites (AMCs). Their use is focused mainly in automotive and aircraft industries due to the importance of material tribological properties in these applications (Senapati et al., 2014; Mazahery \& Shabani, 2013). SiC is a covalent material of huge technological attention thanks to its excellent overall properties. It has good thermal shock behavior and mechanical resistance with has high thermal conductivity, oxidation, and erosion resistances (Liu et al., 2010). The $\mathrm{SiC}$ as whisker or particle reinforced $\mathrm{Al}$ matrix composite (Al-SiC) is perhaps the most successful class of MMCs produced ever (Mandal \& Viswanathan, 2013). As a result, AMCs reinforced with $\mathrm{SiC}$ particles offer higher modulus, wear resistance, and better dimensional stability than conventional aluminum alloys (Mohanakumara et al., 2014).

Powder Metallurgy (PM) can be used to prepare aluminum composites in the solid state. The process consists of mixing reinforcement particles with the metallic powder, followed by consolidation and sintering processes. Other methods that could be also adopted include mechanical alloying (MA) and mechanical milling (MM), which renders composites with fine and homogeneous distributions of the particles (Mazahery \& Shabani, 2013; Showaiter \& Youssefi, 2008; Kim et al., 2001). The best properties of PM for fabrication of composites can be obtained when the reinforcement is homogeneously dispersed in the matrix (Ravindran et al., 2013).

MMCs can be reinforced using alternatives such as continuous fibres, discontinuous particles, or whiskers (Yan et al., 2008). Particle-reinforced MMCs possess distinct advantages over fibre reinforced composites regarding low cost and isotropic mechanical properties considerations. Therefore, they are relatively easier to process via powder compared to AMCs reinforced with ceramic whiskers and fibers (Mazahery \& Shabani, 2012). The mechanical properties of a composite under loading are typically controlled by the interfaces formed between matrix and reinforcement particles. Generally, a good interface bonding with coherency or semi-coherency is advantageous for better mechanical properties. Conversely, interface with in-coherency degrades its properties, especially with the presence of brittle intermetallic phases (Mandal \& Viswanathan, 2013). Discontinuous particles reinforced MMCs have gained much interest recently due to their promising mechanical properties regarding matrix-reinforcement coherency (Mohanakumara et al., 2014; Mazahery \& Shabani, 2013; Zhanwei et al., 2014). Additionally, the common problems accompanying the fabrication of continuous reinforced MMCs such as fiber-damage, microstructural heterogeneity, fiber mismatch, and inter-facial reactions are minimized by the use of discontinuous reinforcements (Kalkanl \& Yilmaz, 2008).

During the last several decades, optimizing the mechanical properties of the $\mathrm{SiC}$ reinforced aluminum alloy composites has been a main point of interest for many researchesrs, for instance (Min, 2009). The improvement of mechanical properties of produced composites could be reached by having a well performed homogenization which would enable uniform distribution of reinforcement particles in the composite matrix. The effectiveness of the powder and the performance of produced components are typically determined by the appropriate relative mixture contents and constituents (Bozic et al., 2010).

In the current study, a quantitative procedure is adopted to explore the effect of the $\mathrm{SiC}$ volume fraction and the $\mathrm{HC}$ temperature on the physical and mechanical properties of AMCs, and to develop a general approach describing the dependence of the relative density and hardness of the AA6061-SiC composite on $\mathrm{SiC}$ content and hot compaction temperature. Based on a previous study (El_Garaihy, 2012), experimental data are used to establish mathematical models of the functional relationship of the aforementioned parameters. Response surface in terms of three dimensions and contours representations are introduced as database reference to help in the design stages.

\section{Materials and Experimental Procedures}

\subsection{Materials}

The investigated aluminum alloy AA6061 (supplied by Powders Company Limited) was received in the form of powders $30 \mu \mathrm{m}$ in average size, Figure 1a. AA6061 particles were characterized by irregularity in shape with variation in size from 10-to-75 $\mu \mathrm{m}$. The as-received $\mathrm{SiC}$ powders (supplied by American Elements Company) were used as reinforcement. As shown in Fig. 1b, $\mathrm{SiC}$ powder was characterized by non-uniformity in shape with particles size ranging from 1-to-5 $\mu \mathrm{m}$ with an average size of $2 \mu \mathrm{m}$. 


\subsection{Experimental Procedures}

To fabricate theAA 6061- SiC metal matrix composite, the required fractions of AA6061 and $\mathrm{SiC}$ powders were mixed under vacuum in a glove box followed by mixing in a turbula mixer operating at a rotation speed of 96 rpm. Four different volume fractions of $\operatorname{SiC}(5,10,15$, and 20\%) were selected to reinforce AA6061 matrices. Both AA6061, AA6061-SiC composites powders were subjected to single sided uniaxial HC into cylindrical sample $10 \mathrm{~mm}$ in diameter and $10 \mathrm{~mm}$ in height. The hot compaction process was carried out at compaction pressure of $525 \mathrm{MPa}$ and temperature of 400,450 , and $500^{\circ} \mathrm{C}$ for $30 \mathrm{~min}$.

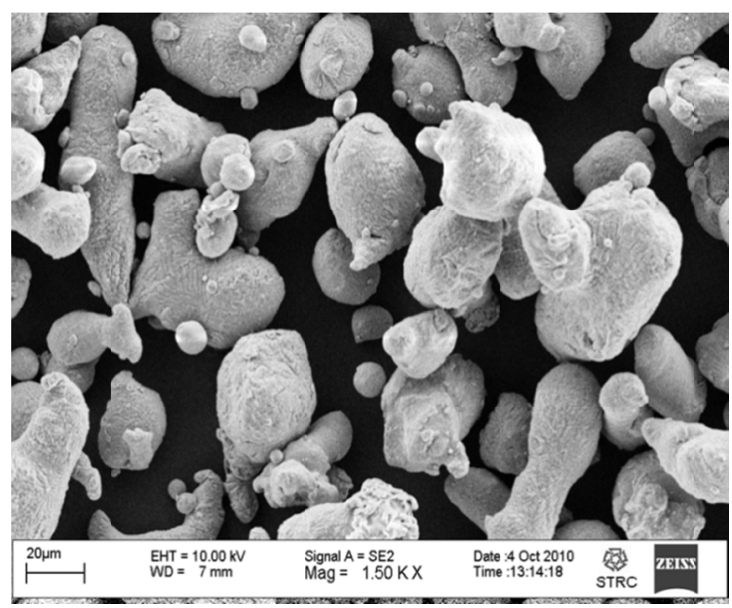

Figure 1a. SEM micrograph of AA6061 powders

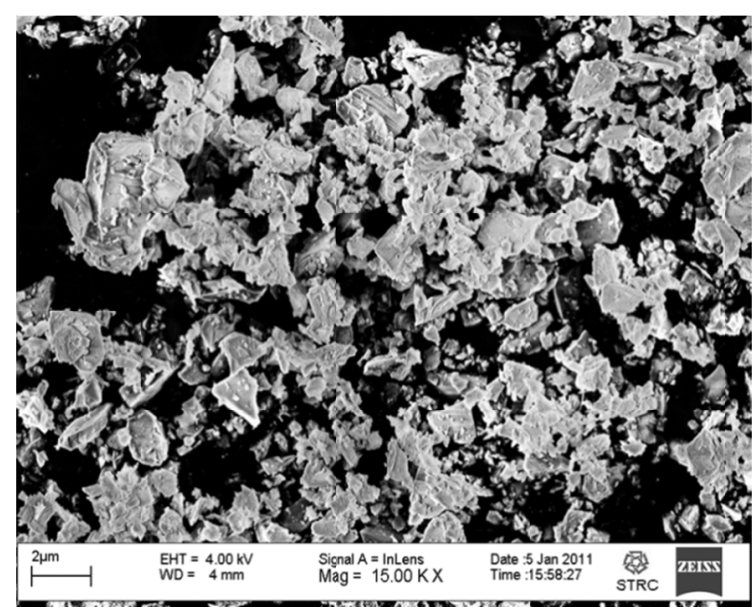

Figure 1b. SEM micrograph of SiC powders

Following HC, the disks were polished to a mirror-like finish. Density measurements were carried out on the base alloy and reinforced samples using a digital densitometer that employs the Archimedean principle for density measurements. Vickers Hardness (Hv) values were measured on the disk sections cut parallel to the loading direction using digital metallic Vickers's hardness tester. Testing was carried out on the surfaces under applied load of $10 \mathrm{~N}$ and a dwell time $15 \mathrm{sec}$ for each separate measurement. The microstructure of the monolithic alloy and the composites were characterized by LICKA inverted metallurgical OM and a LEO field emission scanning electron microscopy (FESEM) operating at 200KV at $1 \mathrm{~nm}$ resolution of ground polished and etched samples using "keller" solution.

\section{Data Processing Modeling Methodology}

\subsection{LinearModeling}

To establish an empirical functional interrelationship between a dependent variable, response (R), and some dependent variables ( $\xi$ 's), a first-order model is usually postulated to take the general form (Douglas et al., 2012; Myres et al., 2012):

$$
R=b o+\sum_{j=1}^{p} b_{j} \xi_{j}+\varepsilon_{n},
$$

where b's are the model estimates (coefficients) and $\varepsilon_{\mathrm{n}}$ is the error absolute value using linear non-transformed model. However, in terms of real parameters, the model takes the final first order multiple linear model:

$$
R=b_{o}+b_{1}\left(x_{1}\right)+b_{2}\left(x_{2}\right)+\ldots \ldots . .+b_{n}\left(x_{n}\right) \text {, }
$$

where $x$ 's are the independent variables.

To take into account the possible interaction and quadratic effect among the independent variables, a second order structure is usually accounted for. For two independent variables $\mathrm{x}_{1}$ and $\mathrm{x}_{2}$, the second order model usually takes the form (Myres et al., 2012):

$$
R=b_{o}+b_{1}\left(x_{1}\right)+b_{2}\left(x_{2}\right)+b_{11}\left(x_{1}^{2}\right)+b_{22}\left(x_{2}^{2}\right)+b_{12}\left(x_{1} \cdot x_{2}\right)
$$

where $b_{i i}$ and $b_{i j}$ are the quadratic and the interaction effects to be determined by fitting the experimental data using the appropriate mathematical technique. 


\subsection{NonlinearModeling}

However, to detect the possible nonlinear nature of the independent variables, a nonlinear model is usually proposed in the form (Myres et al., 2012; Kowalski, 1977):

$$
R=a o \mathrm{x}_{1}^{a 1} \mathrm{x}_{2}^{a 2} \ldots \ldots \ldots x_{n}{ }^{a n},
$$

where a's are the model coefficients to be determined by the nonlinear regression procedures using the experimental data.

Regression statistical routine is used together with the experimental data to reach the most adequate and significant relationship between each of the dependent variable; relative density (RD) and Vicker's hardness $\left(\mathrm{H}_{\mathrm{V}}\right)$, and the independent variables; AA6061 percentage in the alloy $(\mathrm{Al} \%)$ and compact temperature $\left(\mathrm{T}_{\mathrm{HC}}\right)$.

Regression routine is one of the most familiar statistical tool to detect the influence of more than one independent variables are involved. This is a necessity if a response surface is required. Using regression analysis asseses and estimates the effect of each individual variable on the measured response together with the possible interaction effect among all involved variables. As in many modeling and forecasting techniques, such as neural network, genetic algorithm, etc, regression analysis uses the most widely used ordinary least squares analysis. Such a fitting technique is included as a toolbox facility in many commercial programs such as MathWork and MatLab. Least squares method creats the best fit line or surface through all of the available data points so as to minimize error sum of squares. Fitting a regression model requires several assumptions of which the assumption that the errors are uncorrelated random variables with mean zero and constant variance. Also, tests of hypotheses and interval estimation require that the errors are normally distributed. There are a number of advanced statistical tests that can be used to examine whether or not these assumptions are true for any given regression equation (Myres et al., 2012; Kowalski, 1977).

Through the current study, a fitting strategy is followed so as to begin with the first-order model of form (2) then; interaction among dependent variable and their possible quadratic and nonlinear trend are examined using model structures (3) and (4). Fitting procedures are terminated once the best model is detected. Model adequacy and significant is judged through many criteria which can be defined as follow:

- Correlation Factor $\left(R^{2}\right)=[1-($ Residuals Sum Squares $/$ Total Sum Squares $)]$

- $t_{\text {statistics }}$ value $=[$ Predictor Value/Predictor Standard Error $]$

- $\quad F_{\text {ratio }}=$ [Regression Mean Squares /Residuals Mean Squares $]$

Correlation factor $\mathrm{R}^{2}$, sometimes denoted as coefficient of determination, measures the percentage of variation in the response variable $\mathrm{R}$ explained by the explanatory variable $\mathrm{x}$. Thus, it is an important measure of how well the regression model fits the data. The value of $\mathrm{R}^{2}$ is always between zero and one. $\mathrm{R}^{2}$ of unity or, $100 \%$, means all variability are grasped while $50 \%$ or below, indicates the the predictionmay be poor. Student $t_{\text {statistics }}$ value usually measures the influence strength (weight) of an estimated coefficient for a specivic independent variable $\mathrm{x}_{\mathrm{i}}$ through comparing its estimated value to its calculated standard error. For a variable to be significant, $t_{\text {statistics }}$ absolute value must not be less than 2.0. As indicated above, $\mathrm{F}_{\text {ratio }}$ (F-test) indicates the ratio of regression mean squares to the residuals mean squares for a set of independent variables and number of data points (degrees of freedom). This has a preset threshold value from special statistical tables where greater value is not always a judgment of model superiority.

Further statistical judgment (hypothesis tests) is performed by observing the trends of each of the residuals pattern and the normal distribution of the predicted values (Douglas et al., 2012). Based on the selected best model, a surface response representation is introduced in terms of 3-dimensional graphs and contours which will be demonstrated in the following section.

\section{Effect of SiC Content and Compact Temperature on the Relative Density}

The aforementioned fitting strategy is used to establish a relationship between the relative density (RD), as a dependent variable, and AA6061 percent in the alloy and compact temperature $\left(\mathrm{T}_{\mathrm{HC}}\right)$ as independent variables using the experimental data listed in Table 1. To get rid of computational error arises during fitting process at zero $\mathrm{SiC} \%$, AA6061 content ( $\mathrm{Al} \%)$ is transformed and coded so that the value is always greater than zero $(\mathrm{Al} \%=100 \%-\mathrm{SiC} \%)$.

A first-order linear model of form (2) was obtained taking the form:

$$
R D=90.903+0.132(A l \%)-0.13\left(T_{H C}\right)
$$


with $\mathrm{R}^{2}$ of $90 \%$ along with $\mathrm{t}_{\text {statistics }}$ for $\mathrm{b}_{\mathrm{o}}, \mathrm{b}_{1}$ and, $\mathrm{b}_{2}$ are $51,8.7$ and, -5.1 respectively together with $\mathrm{F}_{\text {ratio }}$ value of 52 , the model satisfies the adequacy requirements. Model significance is justified as its residuals are with error zero mean, Figure 2a, error normal distribution, Figure 2b, and random distribution, Figures $2 \mathrm{c}$.

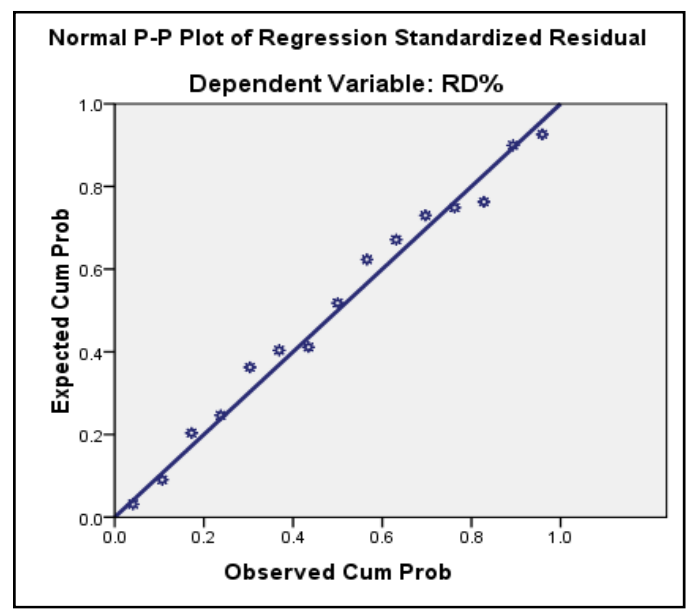

a) Residuals zero-mean hypothesis

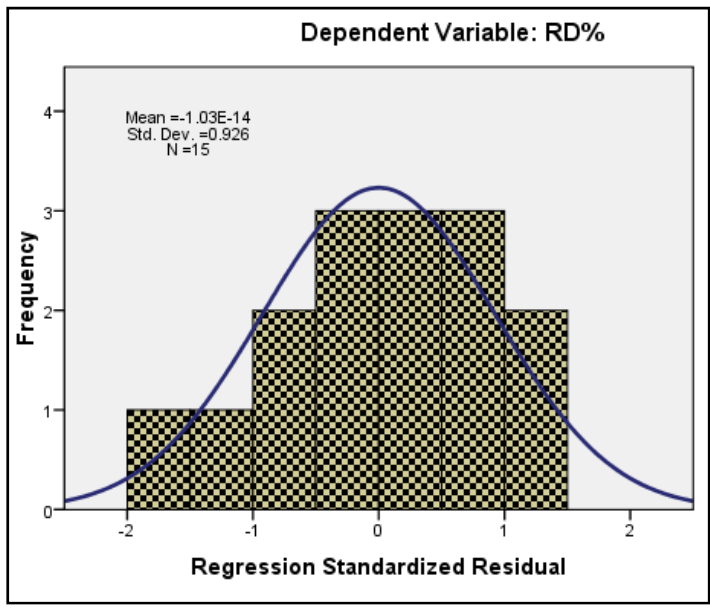

b) Residuals normal probability hypothesis

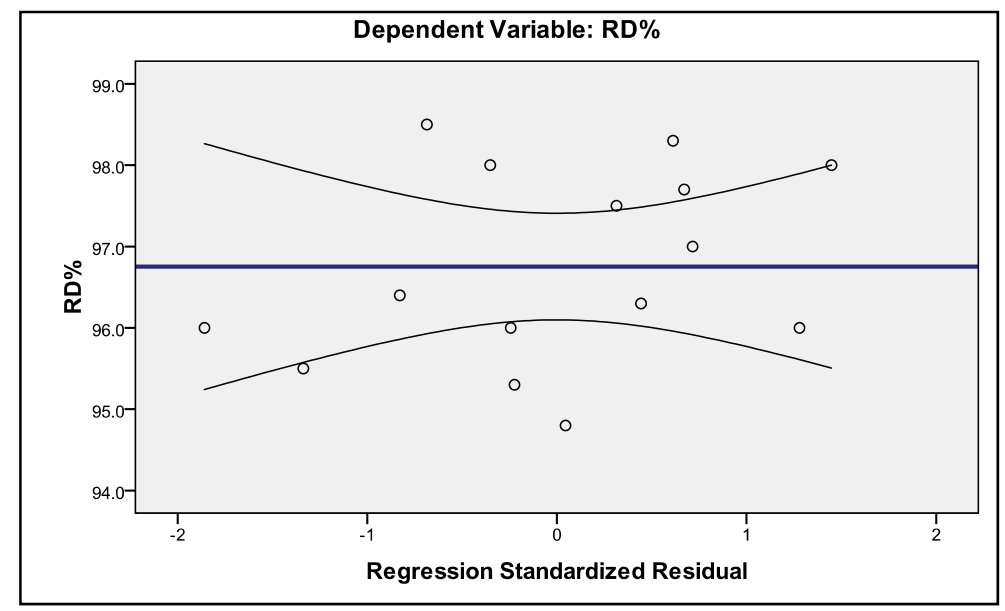

c) Random error distribution hypothesis

Figure 2. Residuals hypothesis tests for the developed model (5)

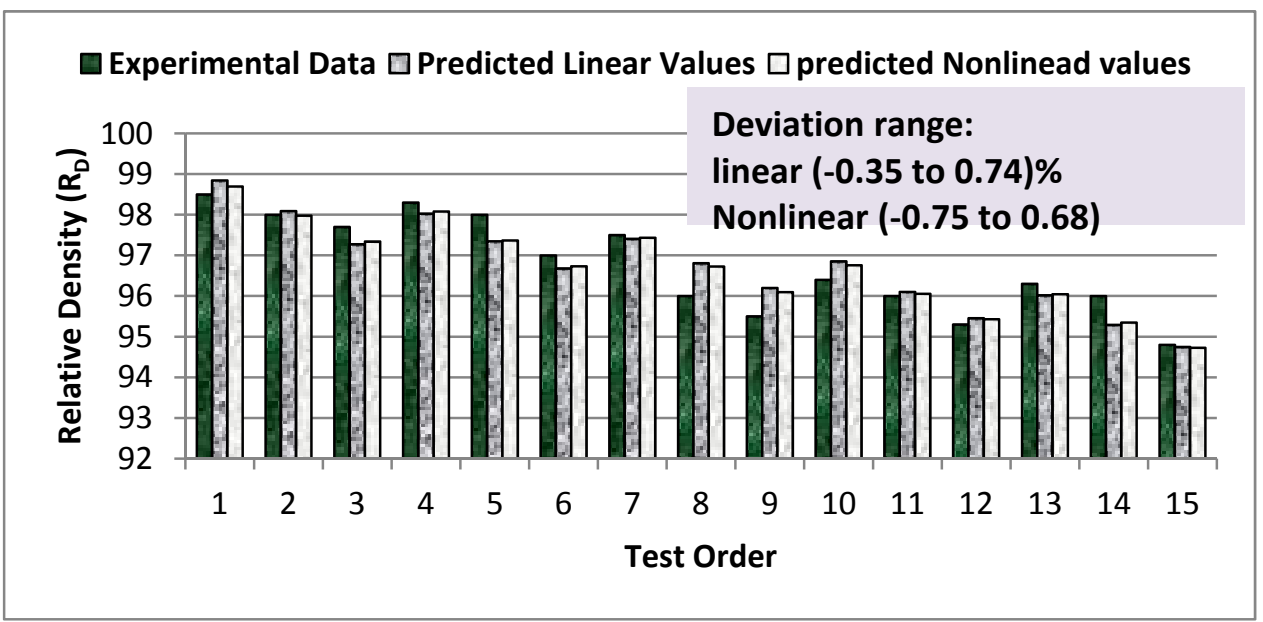

Figure 3. Comparison of experimental and predicted data for both linear and nonlinear models 
For the same set of experimental data, a better model predicatability is seeked through the establishment of the counterpart nonlinear model of form (4). The nonconventional nonlinear iterative regression routine in SPSS program is used according to the default convergenece criteria. For each iteration, the model derivatives are numerically calculated and examined against the specified criterion values. Process continues until it reaches the best model with minimum squares of residuals relevant to the specified criteria. This process has led to the model (6).

For practical predictability comparison between the linear and nonlinear models, Figure 3 is dedicated to indicate how predicted (estimated) value from each structure is close to its counterpart experimental value, Table 1.

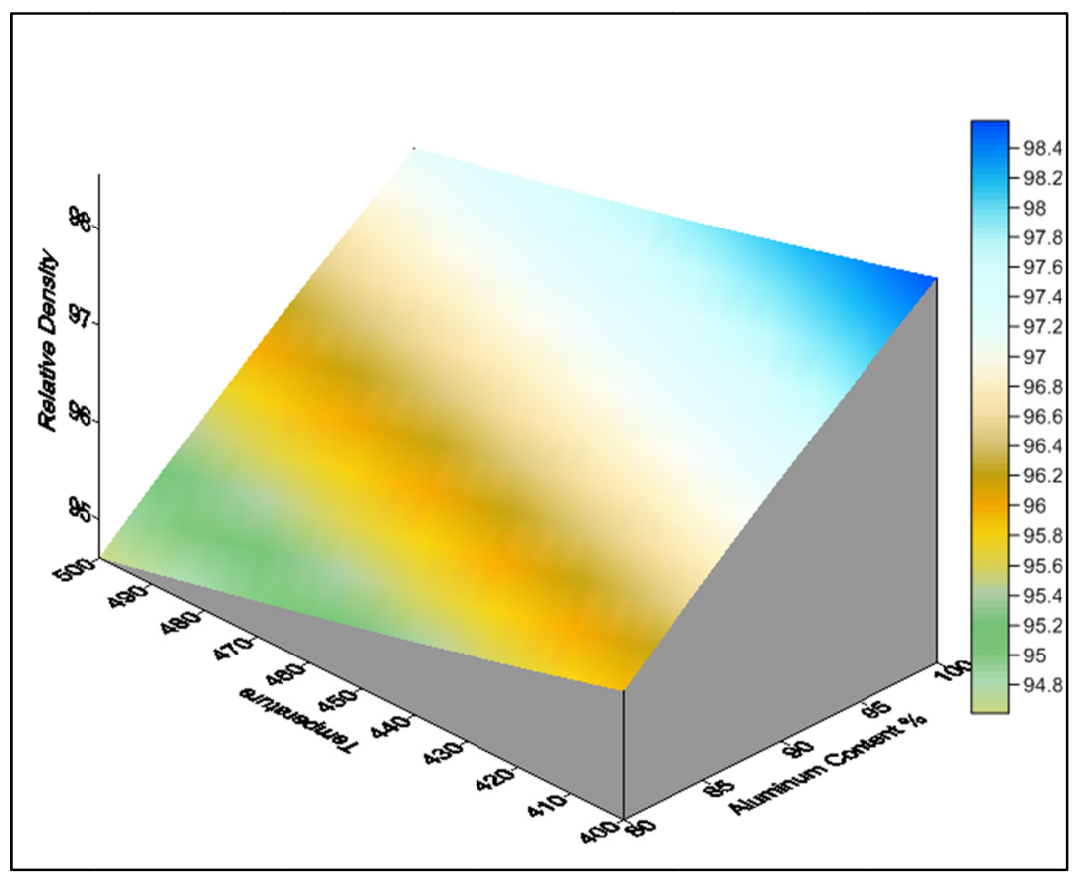

a) $\mathrm{Al} \%-\mathrm{T}_{\mathrm{HC}}-\mathrm{RD} \%$ response surface

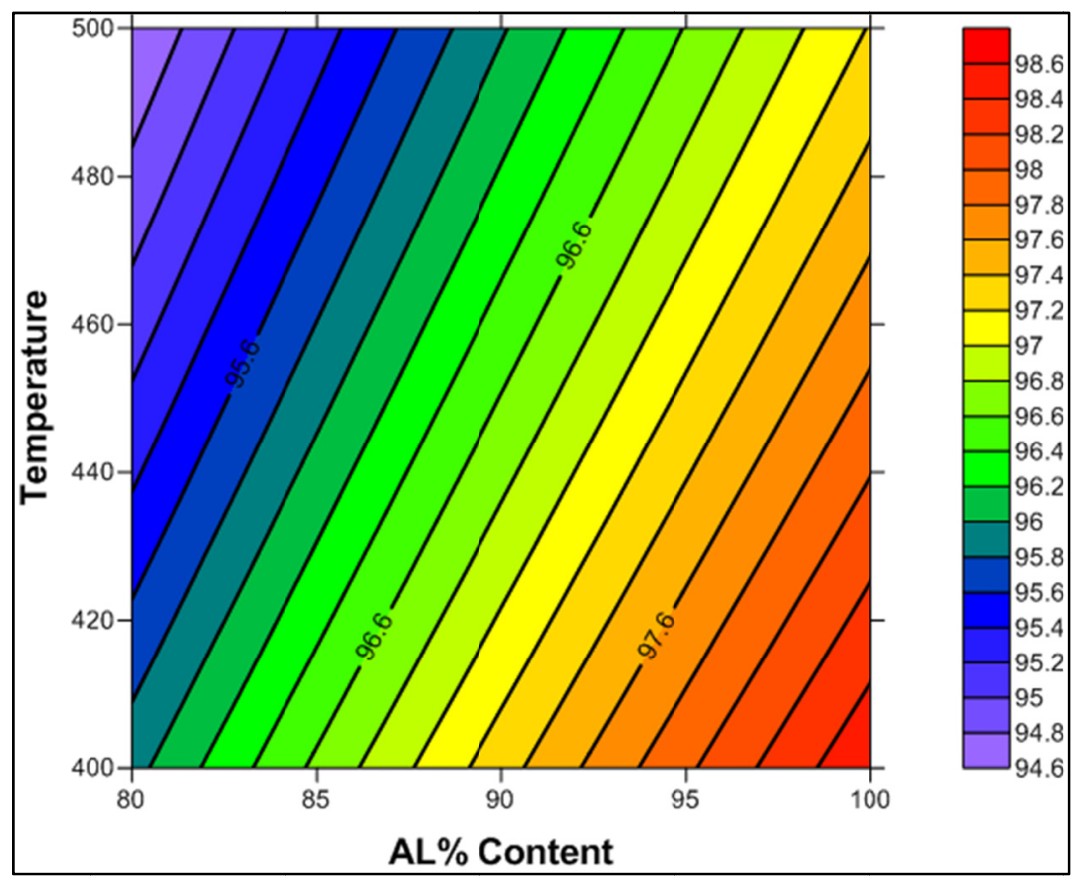

b) $\mathrm{Al} \%-\mathrm{T}_{\mathrm{HC}}-\mathrm{RD} \%$ Contour graph

Figure 4. Surface response of the influence of AA6061\% and temperature on the relative density 
While a deviation range of (-0.35 to 0.74$) \%$ is obtained considering the linear model (5), a wider deviation is noticed for the nonlinear one (6). Furthermore, no interaction or second order trends of the independent variables, $\mathrm{Al} \%$ and $\mathrm{T}_{\mathrm{HC}}$, prove credibility to be included in the model.

Therefore, it is concluded that a first order linear model is adequate and significant enough to represent the set of experimental data for which it was developed.

$$
R D=81.589(\mathrm{Al} \%)^{0.122}\left(\mathrm{~T}_{\mathrm{HC}}\right)^{-0.062}
$$

Figure 4 shows the surface response with contour graph of the influence of AA6061 vol fraction and HC temperature on the RD. As numerically explained by model (5), the relative density slightly decreased as HC temperature increased. This is thought, on the first hand, due to the formation of voids in the cooling stage that is associated with variation in the coefficient of thermal expansion (CTE) of the AA6061 matrices $(a=23.6 * 10-6$ $\left.1{ }^{\circ} \mathrm{C}\right)$ and the $\mathrm{SiC}\left(\mathrm{a}=2.77 * 10-6 /{ }^{\circ} \mathrm{C}\right)$. As $\mathrm{HC}$ temperature increases, both voids volume fraction and residual stresses increase leading to deterioration in density (Salem et al., 2009). On the other hand, model coefficients and graphs embody the intuitive relationship where lower $\mathrm{SiC}$ content improves the $\mathrm{HCs}$ density at any $\mathrm{HC}$ temperatures. Monolithic aluminum alloy powder possesses good compressibility that is reduced as hard $\mathrm{SiC}$ particles (which possess low compressibility) are added and, consequently, the relative density decreases. Adding brittle $\mathrm{SiC}$ into ductile matrix of AA6061 leads to the segregation between the reinforcement and matrix at the triple junctions and along grain boundaries and, this widespread as $\mathrm{SiC}$ reinforcement content increases as shown in Figure 5. This could be verified by the microstructure, where increasing the amount of voids is proportional to the increase in amount of $\mathrm{SiC}$ content, as shown in Figure 6. $\mathrm{SiC}$ resulted in the formation of isolated voids which coalesced into larger voids and cavities when $\mathrm{SiC}$ content increased.

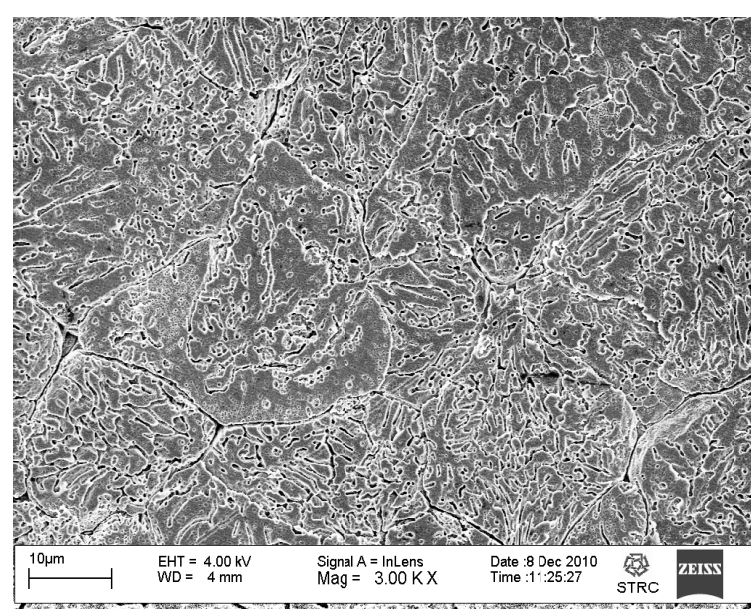

(a)

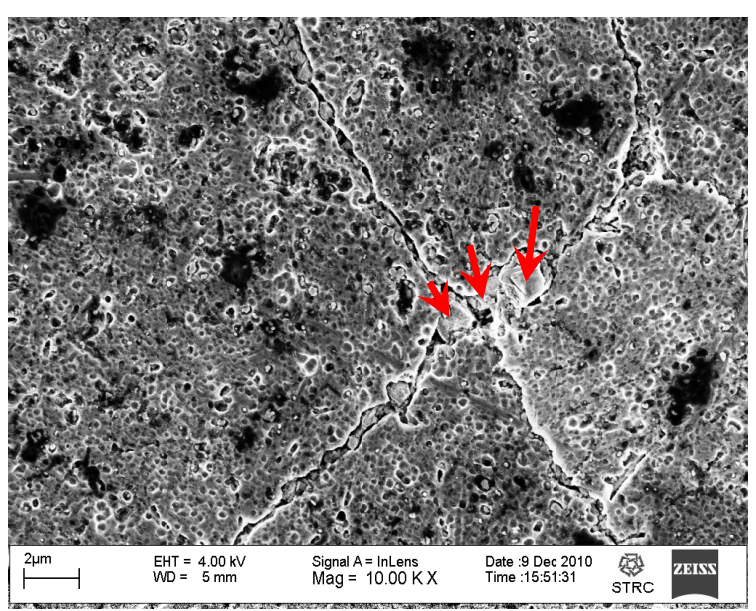

(b)

Figure 5. SEM micrographs of (a) AA6061 and (b) AA6061+15vol. $\% \mathrm{SiC}_{\mathrm{p}} \mathrm{HC}$ at $400{ }^{\circ} \mathrm{C}$, arrows point at $\mathrm{SiC}$ particles

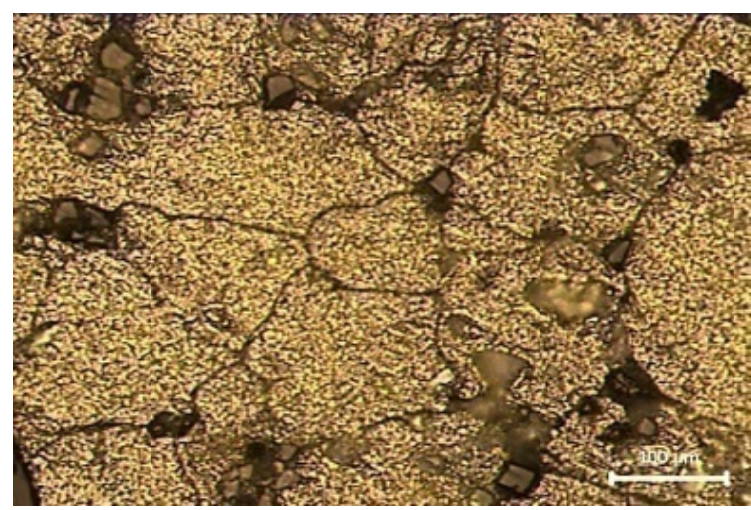

(a)

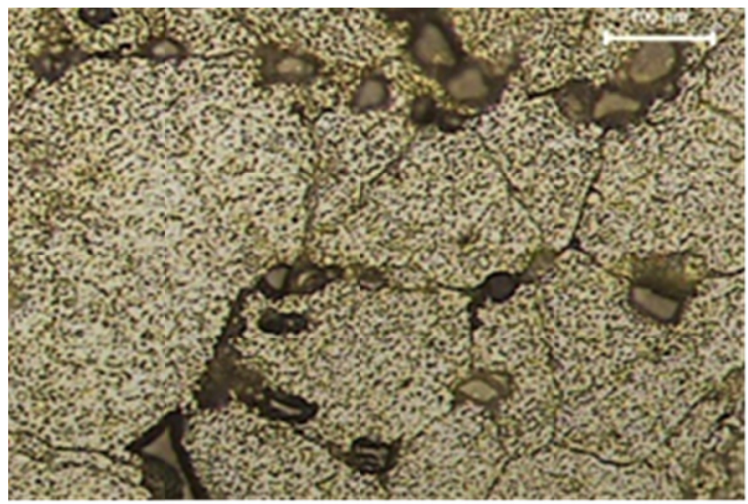

(b)

Figure 6. OM micrographs of AA6061- $15 \mathrm{vol} \% \mathrm{SiC}_{\mathrm{p}}$ hot compacted at (a) $400{ }^{\circ} \mathrm{C}$, and (b) $500^{\circ} \mathrm{C}$ 


\section{Effect of SiC Content and Temperature on the Hardness}

Same fitting procedures and strategy, which has been explained in the last section, are followed to develop a functional interrelationship between the alloy hardness (Vickers Hv) as a dependent variable and both of the AA6061 content $(\mathrm{Al} \%)$ and $\mathrm{HC}$ temperature $\left(\mathrm{T}_{\mathrm{HC}}\right)$ as influential independent variables.

Applying a first order linear multiple form (2) didn't lead to satisfactory general statistical outcome. To resolve such an emerged problem, the partial plots are considered to reveal the individual real natural dependence of $\mathrm{Hv}$ on each of $\mathrm{Al} \%$ and $\mathrm{T}_{\mathrm{HC}}$, Figure 7. Hardness-AA6061 content, Figure 7a, exhibits a strong indication of second-order (quadratic) trend while an almost linear trend is noticed regarding hardness-temperature dependency, Figure 7b. Consequently, a second-order multiple regression of form (3) is proposed. Using Stepwise procedure in linear regression routine, which determines the maturity of each individual independent variable to be included into the final equation, the following second order linear model is obtained:

$$
H V=424.17-0.081(A l \%)^{2}-0.082\left(T_{H C}\right)+13.325(A l \%)
$$

with $\mathrm{R} 2=93.7 \%$, t_values $=-2.4,-4.3,-4.3$ and 3.94 and, F_ratio $=54$, the developed model is considered adequate and significant to represent the relevant functional interrelationship.

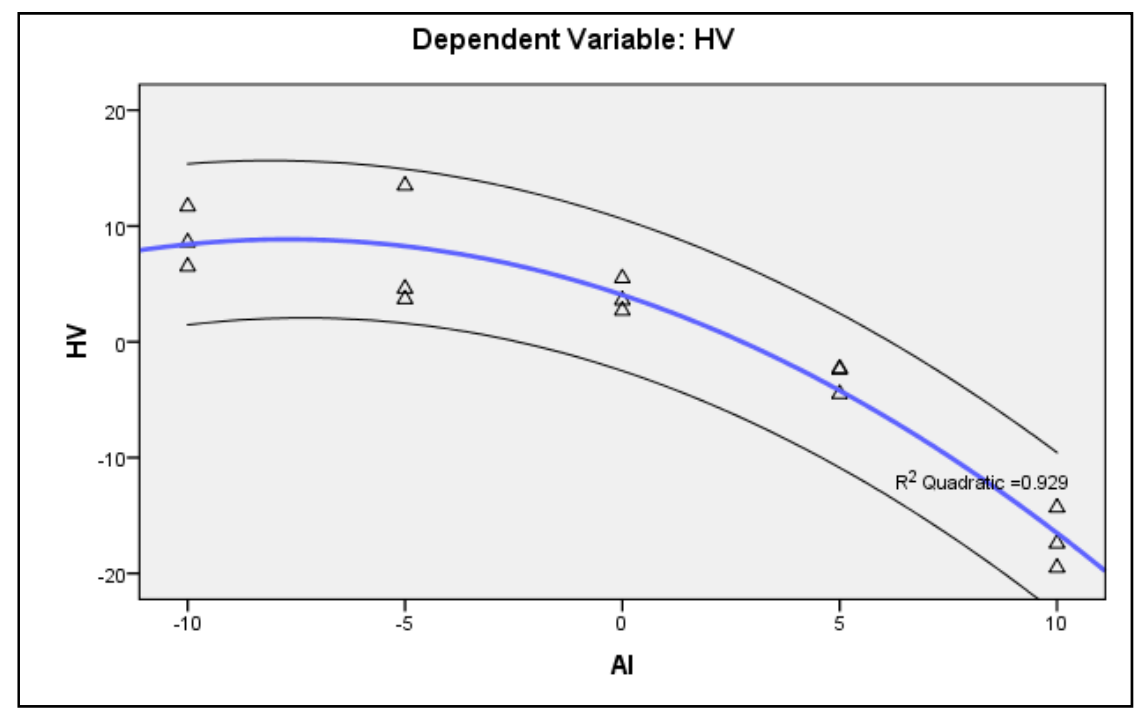

a) Quadratic component in the $\mathrm{Hv}-\mathrm{Al} \%$ real relationship

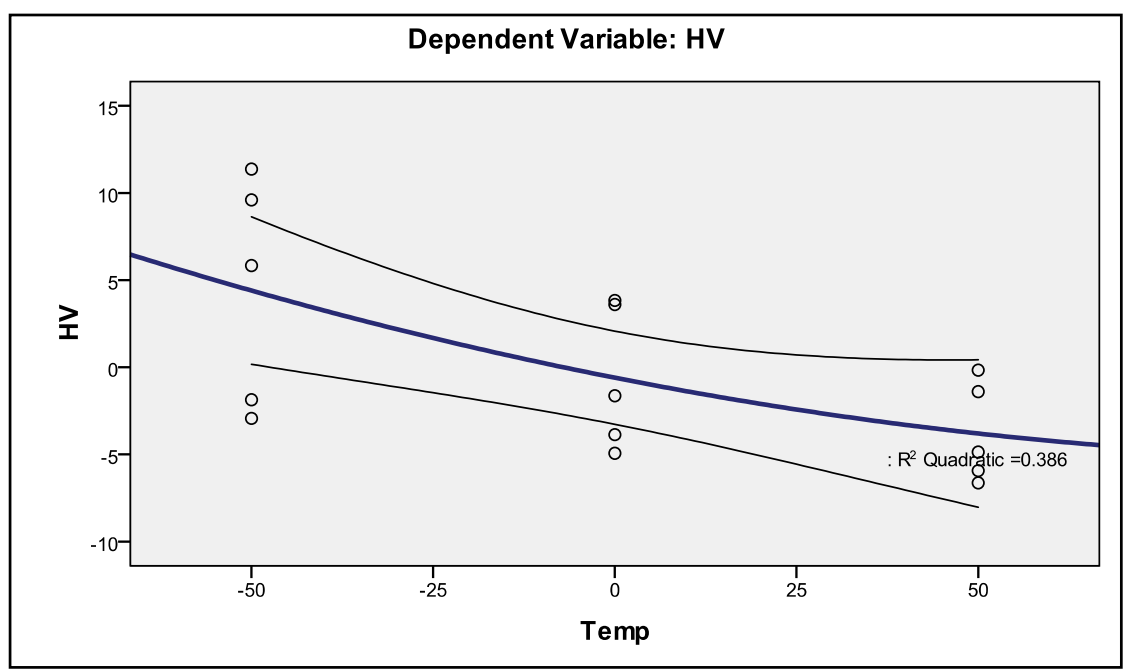

b) $\mathrm{Hv}-\mathrm{T}_{\mathrm{HC}}$ relationship

Figure 7. Partial relation between hardness and each of AA6061 content and temperature 
Residuals examination shows nothing against its zero mean, normal probability and, randomness distribution, Figure 8.

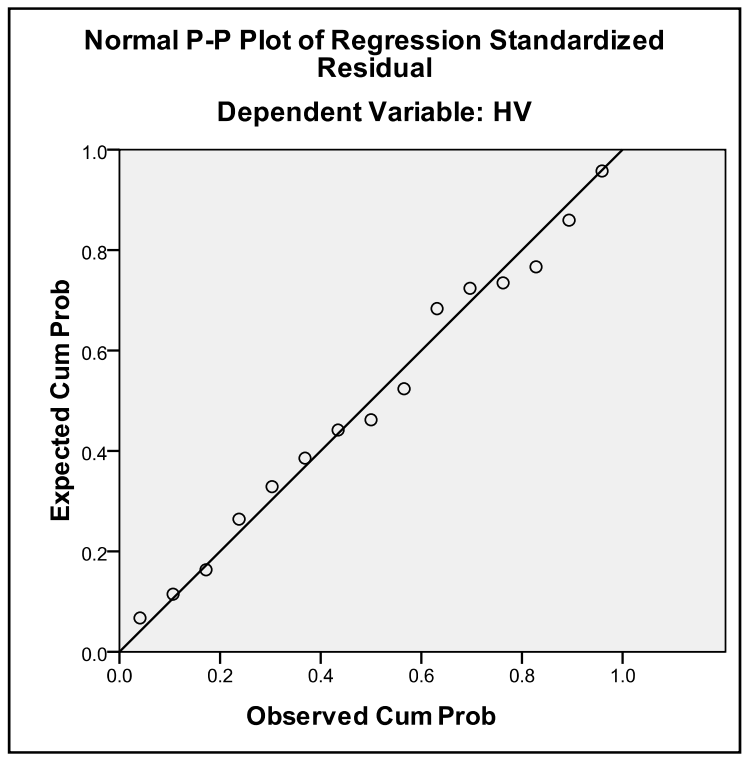

a) Residuals zero-mean hypothesis

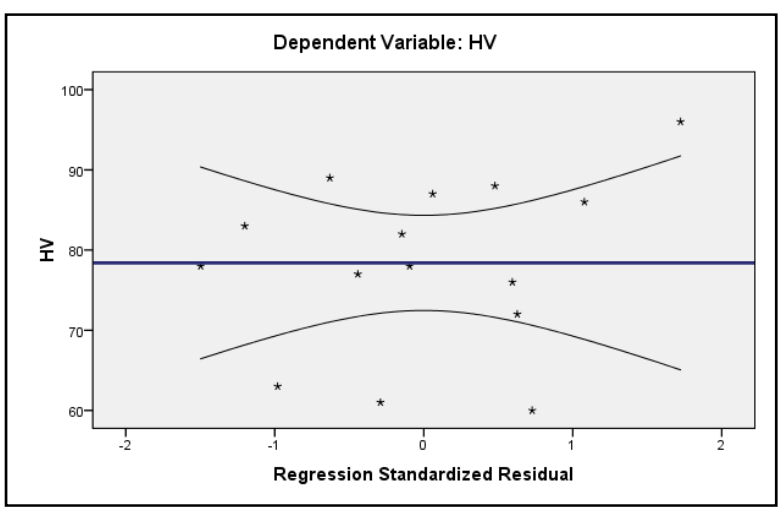

b) Random error distribution hypothesis

Figure 8. Residuals zero mean, normality, and random distribution of multiple regression model (7)

An equivalent iterative no-linear model is found to have the following structures:

$$
H V=602469.152(\mathrm{Al} \%)^{-1.348}\left(\mathrm{~T}_{\mathrm{HC}}\right)^{-0.474}
$$

with less correlation factor R2 of 87.7 and, therefore, it is of less predictability than model (7) to predict values of $\mathrm{Hv}$ as a relation to both AA6061 content $(\mathrm{Al} \%)$ and $\mathrm{HC}$ temperature $\left(\mathrm{T}_{\mathrm{HC}}\right)$. This may be observed from Figure 9 where both models are examined against the experimental values. As shown by Figure 9.b, nonlinear model exhibits larger deviations from the experimental values especially for experiments Nos. 1, 2, 3, 13 and 14 with overestimation trend. For the rest of cases, an approximate trend is observed for both models credibility. However, both models tend to represent the effect of reducing AA6061\% or, increasing SiC\%, on the hardness of the composite. It is obvious that a reinforced disc has a Hv-value higher than the monolithic alloy. However compact temperature seems to have a limited influence on the hardness. At higher HC temperature, the grain coarsening increases thus lower HV-values result.

Figure 10 shows a 3-D surface response along with a contour graph of the functional $\mathrm{Hv}-\mathrm{Al} \%-\mathrm{T}_{\mathrm{HC}}$ relationship. The effect of $\mathrm{HC}$ temperature has a higher impact of the hardness of monolithic material than on the composite. As $\mathrm{SiC}$ percent increases up to $18 \%$, hardness increases reaching its ultimate value. Further increase in SiC content seems not to affect composite hardness which is slightly and linearly decreases according to a temperature-dependent pattern.

The hardness distribution results showed that good sintering was achieved in the case of AA6061 with or without $\mathrm{SiC}$ reinforcement even at the $400^{\circ} \mathrm{C}$ sintering temperature and adhesion between particles increase as the sintering temperature increase. When temperature rises, the resulting heat leads to the expansion of an aluminum particle making a wider contact with the neighbor particle. As a result, voids between particles are reduced. Furthermore, increasing $\mathrm{HC}$ temperature up to $500^{\circ} \mathrm{C}$ usually leads to strain softening due to grain coarsening as shown in Figure 6.

The presence of the $\mathrm{SiC}$ increased the composite hardness as they carry some of the load applied to the material (load transfer from the matrix to the reinforcement due to the difference in the elastic constant). The increase in the Hv-values of the composite can be attributed to the high hardness of the reinforcement. So mainly the interaction is either aluminum with aluminum particles which adhere properly or aluminum with $\mathrm{SiC}$ in which adhesion is enhanced by the presence of $\mathrm{SiC}$ particle. 
It is important to emphasize the fact that the grain size of the processed AA6061 was reduced with SiC addition, where the $\mathrm{SiC}$ particles assisted in hindering the grain growth by pinning the grain boundaries and inhibiting grain boundary migration and they also locked the grain boundaries which elevate its strength. The presence of $\mathrm{SiC}$ particles at the grain boundaries and at the triple junctions promoted good sites for hindering the dislocation motion and grain growth. Dislocation piling at the boundaries resulted in increasing resistance to deformation and hence higher strength and hardness. SiC particles being hard and brittle led to dispersion hardening of the matrix. The resistance to slip was increased with increasing $\mathrm{SiC}$ particles content because the overall lattice strain must increase if a dislocation is torn away from them. The excess dislocations within grains and near grain or subgrain boundaries which increased by increasing the $\mathrm{SiC}$ content, made dislocation glide more difficult. Thus, the imposed stress necessary to deform a metal increased, and hence the hardness of the composite revealed to be higher than of the alloy.

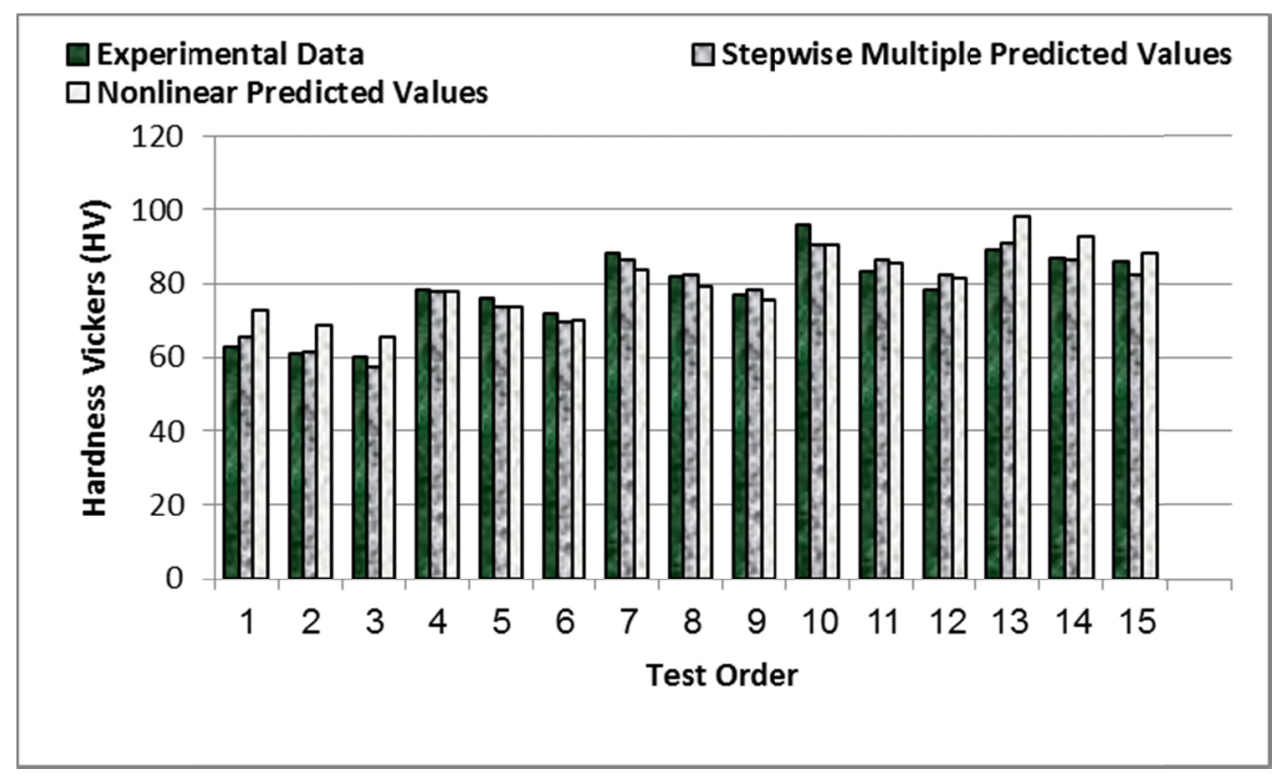

(a) Experimental-second order linearc-nonlinear comparison of predicted values

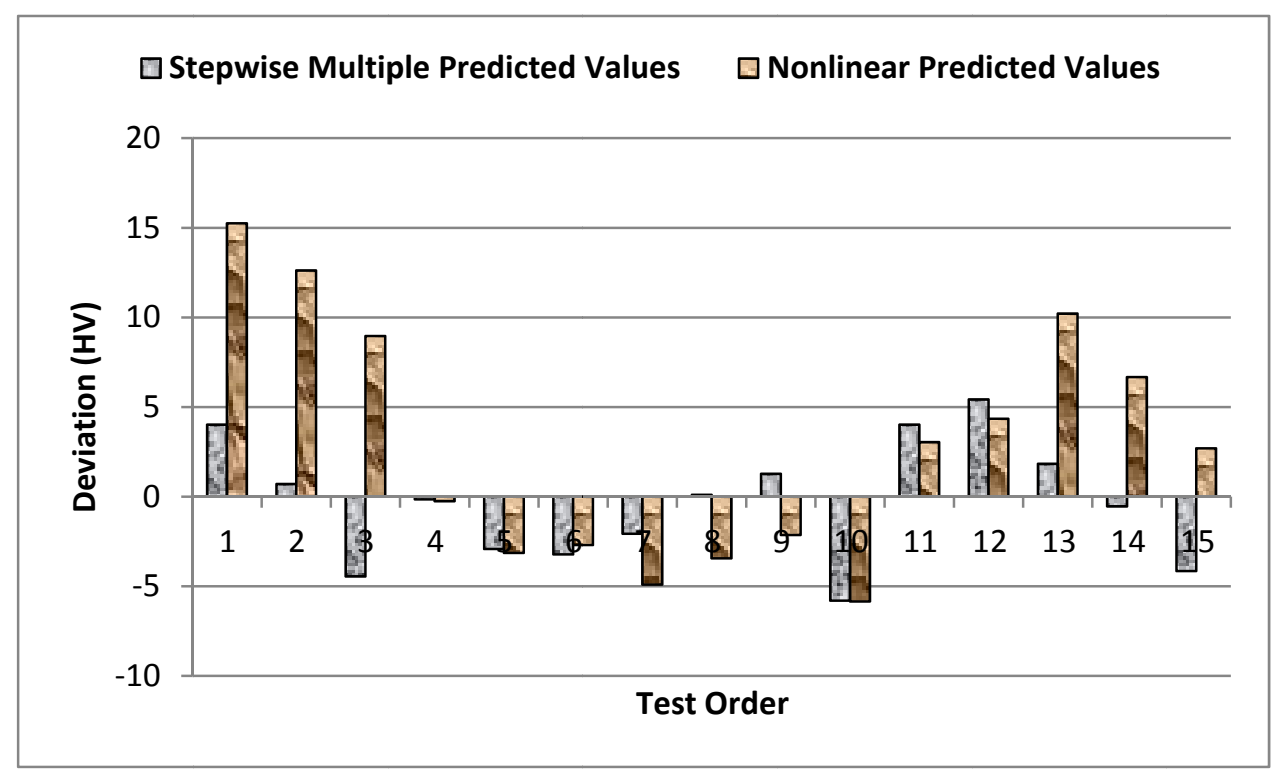

(b) Predictability comparison between second order linear stepwise and nonlinear regression models

Figure 9. Stepwise multiple second order linear vs nonlinear models 


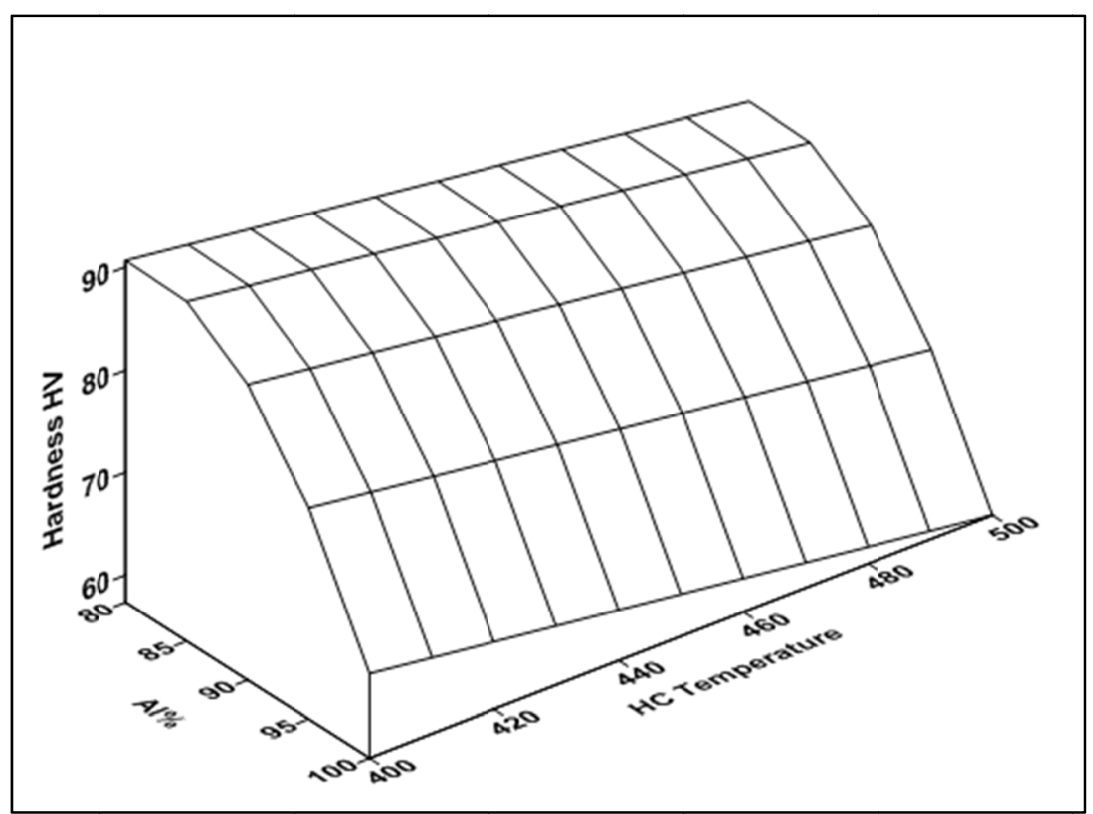

a) $\mathrm{HV}-\mathrm{Al} \%-\mathrm{T}_{\mathrm{HC}}$ response surface

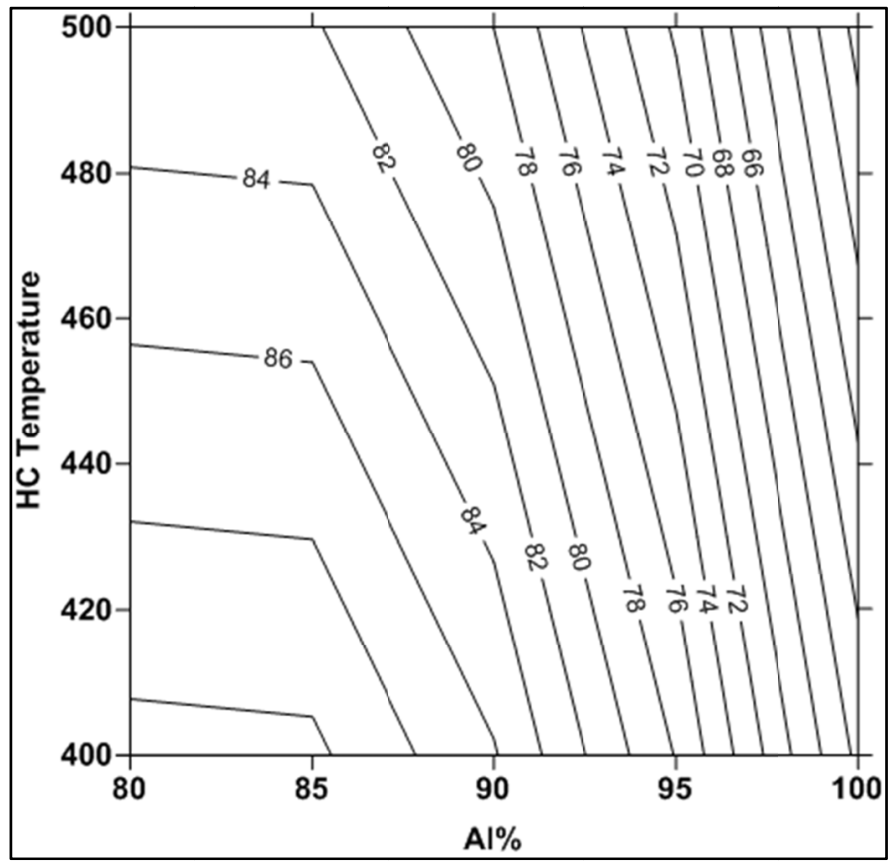

b) $\mathrm{HV}-\mathrm{Al} \%-\mathrm{T}_{\mathrm{HC}}$ contour graph

Figure 10. Surface response and contour graph of the influence of AA6061 content and temperature on the hardness

As shown by Figure 10a, Hv decreases at 100\% Al content while such a trend gradually dimenshes as $\mathrm{SiC} \%$ increases until it almost vanishes at about $85 \% \mathrm{Al}$ content $(15 \% \mathrm{SiC})$. This is graphically evident as area of surface that represents hardness values becomes almost parallel to the horizontal plane suggesting that there is no further change in the hardness values. Such observation is evident in the contour graph, Figure 10.b at given $\mathrm{T}_{\mathrm{HC}}=450$, where $\mathrm{Hv}$ increases from 62 to 82 (about 32\% increase) within the interval 90 to $100 \mathrm{Al} \%$ while a corresponding increase within the interval 85 to $90 \mathrm{Al} \%$ is only $3.7 \%$ ( from 82 to $85 \mathrm{HV}$ increase). As $\mathrm{SiC} \%$ increases after this point, Hv seems not to be affected. Similar observation may be noticed at any HC temperature within the considered domain (from 400 to 500, Fig. 10.b. This indicates that increasing SiC content more than about $15 \%$ does not affect the hardness. Increasing SiC content usually motivies the SiC particles contact and also increases 
the clustering of $\mathrm{SiC}$ particles chances which dramatically affect the material properties. This agrees with the experimatal observations, Figure 11, where at $20 \% \mathrm{SiC}$ composite, the hardness drops due to the weak contact among $\mathrm{SiC}$ particles and, as aresult, higher probability of more than two particle cluster together occurs, Figure 11. Additionally, such decrease in hardness of the AA6061- 20\% $\mathrm{SiC}_{\mathrm{p}}$ composite can be attributed to the decreasing of the composite compressibility which resulted in increasing voids. The porosity volume fraction dominated the behavior of the composite which resulted in deterioration of the overall hardness of the discs. This probably reflects mixing difficulties in obtaining a uniform particle distribution at high volume fraction for this process, there being a higher number of nucleation sites present for the cracks to form as a result of the particle clusters.

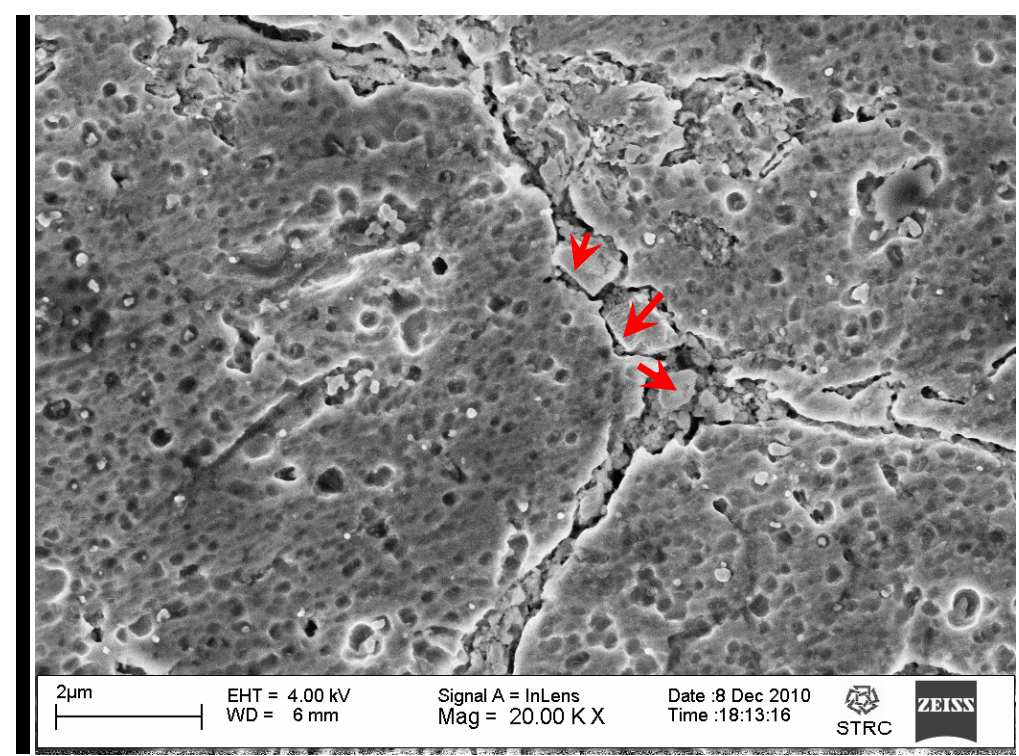

Figure 11 SEM Micrograph for AA6061-20\% SiC showing the segregation of SiC particles along boundaries and triple points, arrows point at $\mathrm{SiC}$ particles

\section{Conclusions}

Different volume fractions of $\mathrm{SiC}$ are added to the monolithic aluminum AA6061. Mixture is hot compacted at various $\mathrm{HC}$ temperatures and both the relative product density and Vickers hardness are recorded. Linear and nonlinear model structures are proposed with sequential preference strategy and robust statistical criterion judgment measures of the model predictability and residuals pattern examination. Although, in many current cases, linear model structure is sufficient for predictability purposes, the need for nonlinear forms is still required to obtain better and more representative respose surface regarding the functional interrelationship considered.

Increasing $\mathrm{SiC}$ content is found to reduce the relative density and to increase the hardness of the composites. However, the surface response and the contour graphs interestingly explained that adding greater than (15 to $20 \%) \mathrm{SiC} \%$ to the composite does not benefit increasing of its hardness. HC temperature showed a negative trend (decrease) in each of the composite relative density and its hardness.

\section{Acknowledgements}

The authors are grateful to Youssef Jamil Science and Technology Research Center (YJSTRC), and the Mechanical Engineering Department, The American University in Cairo- Egypt, for financial support and continuous assistance of their lab engineers and research assistances.

\section{References}

Bozic, D., Dimcic, B., Dimcic, O., Stasic, J., \& Rajkovic, V. (2010). Influence of SiC particles distribution on mechanical properties and fracture of DRA alloys. Materials and Design, 31(1), 134-141. http://dx.doi.org/ 10.1016/j.matdes.2009.06.047

Douglas, C. M., Elizabeth, A. P., \& Geoffrey, G. V. (2012). Introduction to Linear Regression Analysis. 5th Edition, Publisher: John Wiley \& Sons. Retrieved from http://eu.wiley.com/WileyCDA/WileyTitle/ productCd-0470542810.html 
El_Garaihy, W. H. (2012). Production of Ultra Hard Nanostructured Materials. Ph.D Thesis, Man. Un., Egypt. Retrieved from http://www.eulc.edu.eg/eulc_v5/Libraries/Thesis/BrowseThesisPages.aspx?fn=PublicDraw Thesis\&BibID $=11842944$.

Huang, J. C., Shin, C. S., \& Chan, S. L. I. (2004). Effect of temper, specimen orientation and test temperature on tensile and fatigue properties of wrought and PM AA6061-alloys. International Journal of Fatigue, 26, 691-703. http://dx.doi.org/10.1016/j.ijfatigue.2003.11.006

Kalkanl, A., \& Y1lmaz, S. (2008). Synthesis and characterization of aluminum alloy 7075 reinforced with silicon carbide particulates. Materials and Design, 29, 775-780. http://dx.doi.org/10.1016/j.matdes.2007.01.007

Kim, W. J., Hong, S. H., \& Lee, J. H. (2001). Superplasticity in PM 6061 Al alloy and elimination of strengthening effect by reinforcement in super plastic PM aluminium composites. Mat. Sc. and Engineering A, 298(1-2), 166-173. http://dx.doi.org/10.1016/S0921-5093(00)01341-1

Kowalski, B. R. (1977). Chemometrics: Theory and Application. ACS Publications. http://dx.doi.org/10.1021/ bk-1977-0052

Liu, G., Muolo, W., Valenza, F., \& Passerone, A. (2010). Survey on wetting of SiC by molten metals. Ceramics International, 36(4), 1177-1188. http://dx.doi.org/10.1016/j.ceramint.2010.01.001

Mandal, D., \& Viswanathan, S. (2013). Effect of heat treatment on microstructure and interface of SiC particle reinforced 2124 Almatrix composite. Materials Characterization, 85, 73-81. http://dx.doi.org/10.1016/ j.matchar.2013.08.014

Mazahery, A., \& Shabani, M. O. (2013). Microstructural and abrasive wear properties of SiC reinforced aluminum-based composite produced by compocasting. Trans. Nonferrous Met. Soc., 23, 1905-1914. http://dx.doi.org/10.1016/S1003-6326(13)62676-X

Mazahery, A., \& Shabani, M. O. (2012). Nano-sized silicon carbide reinforced commercial casting aluminum alloy matrix: Experimental and novel modeling evaluation. Powder Technology, 217, 558-565. http://dx.doi.org/10.1016/j.powtec.2011.11.020

Min, S. (2009). Effect of volume fraction of Sic particles on mechanical properties of SiC/Al composites. Transactions of Nonferrous Metals Society of China, 19(6), 1400-1404. http://dx.doi.org/10.1016/ S1003-6326(09)60040-6

Mohanakumara, K. C. M., Rajasheker, H., Ghanara, S., \& Ajitprasad, S. L. (2014). Development of Mechanical Properties of SiC Reinforced Cast and Extruded Al Based MMC. Procedia Materials Science, 5, 934-943. http://dx.doi.org/10.1016/j.mspro.2014.07.381

Myers, R. H, Montgomery, D. C., Vining, G. G., \& Robinson, T. J. (2012). Generalized Linear Models: With Applications in Engineering and the Sciences (2nd ed.). John Wiley \& Sons. http://dx.doi.org/10.1002/ 9780470556986

O'Donnell, G., \& Looney, L. (2001). Production of aluminium matrix composite components using conventional PM technology. Materials Science and Eng. A, 303(1-2), 292-301. http://dx.doi.org/10.1016/S0921-5093 (00)01942-0

Pawar, P. B., \& Utpat, A. A. (2014). Development of Aluminium Based Silicon Carbides Particulate MMC for Spur Gear. Procedia Materials Science, 6, 1150-1156. http://dx.doi.org/10.1016/j.mspro.2014.07.187

Rao, R. N., \& Das, S. (2011). Effect of SiC content and sliding speed on the wear behavior of aluminum matrix composites. Materials and Design, 32(2), 1066-1071. http://dx.doi.org/10.1016/j.matdes.2010.06.047

Ravindran, P., Manisekar, K., Kumar, S. V., \& Rathika, P. (2013). Investigation of microstructure and mechanical properties of aluminumhybrid nano-composites with the additions of solid lubricant. Materials and Design, 51, 448-456. http://dx.doi.org/10.1016/j.matdes.2013.04.015

Salem, H. G., El-Eskandarany, S., Kandil, A., \& Abdul-Fatah, H. (2009). Bulk Behavior of Ball Milled AA2124 Nanostructured Powders Reinforced with SiC. Journal of Nanomaterials, 1-12. http://dx.doi.org/10.1155/ 2009/479185

Senapati, A. K. , Ganguly, R. I., Dash, R. R., Mishra, P. C., \& Routra, B. C. (2014). Production, characterization and analysis of mechanical properties of a newly developed novel aluminium-silicon alloy based metal matrix composites. Procedia Materials Science, 5, 472-481. http://dx.doi.org/10.1016/j.mspro.2014.07.290 
Showaiter, N., \& Youssefi, M. (2008). Compaction, sintering and mechanical properties of elemental $6061 \mathrm{Al}$ powder with and without sintering aids. Material and Design, 29(4), 752-762. http://dx.doi.org/10.1016/ j.matdes.2007.01.027

Yan, C., Lifeng, W., \& Jianyue, R. (2008). Multi-functional SiC/Al composites for aerospace applications. Chinese Journal of Aerospace, 21, 578-584. http://dx.doi.org/10.1016/S1000-9361(08)60177-6

Zakaria, H. M. (2014). Microstructural and corrosion behavior of Al/SiC metal matrix composites. Ain Shams Engineering Journal, 5(3), 831-838. http://dx.doi.org/10.1016/j.asej.2014.03.003

Zhanwei, Y., Fuguo, L., Peng, Z., Bo, C., \& Fengmei, X. (2014). Mechanical properties study of particles reinforced aluminum matrix composites by micro-indentation experiments. Chinese J. of Aer., 27(2), 397-406. http://dx.doi.org/10.1016/j.cja.2014.02.010

\section{Appendix A}

Table 1. Experimental Date used in the analysis

\begin{tabular}{llllll}
\hline No & $\mathrm{SiC}^{2} \%$ & Temperature $^{\circ} \mathrm{C}$ & Relative Density RD $\%$ & Vicker's Hardness Hv & AA6061\% \\
\hline 1 & 0 & 400 & 98.5 & 63 & 100 \\
2 & 0 & 450 & 98 & 61 & 100 \\
3 & 0 & 500 & 97.7 & 60 & 100 \\
4 & 5 & 400 & 98.3 & 78 & 95 \\
5 & 5 & 450 & 98 & 76 & 95 \\
6 & 5 & 500 & 97 & 72 & 95 \\
7 & 10 & 400 & 97.5 & 88 & 90 \\
8 & 10 & 450 & 96 & 82 & 90 \\
9 & 10 & 500 & 95.5 & 77 & 90 \\
10 & 15 & 400 & 96.4 & 96 & 85 \\
11 & 15 & 450 & 96 & 83 & 85 \\
12 & 15 & 500 & 95.3 & 78 & 85 \\
13 & 20 & 400 & 96.3 & 89 & 80 \\
14 & 20 & 450 & 96 & 87 & 80 \\
15 & 20 & 500 & 94.8 & 86 & 80 \\
\hline
\end{tabular}

\section{Copyrights}

Copyright for this article is retained by the author(s), with first publication rights granted to the journal.

This is an open-access article distributed under the terms and conditions of the Creative Commons Attribution license (http://creativecommons.org/licenses/by/3.0/). 